\title{
BDNF VAL66MET Polymorphism Elevates the Risk of Bladder Cancer via MiRNA-146b in Micro-Vehicles
}

\author{
Cong Li Xing Zeng Zheng Liu Fan Li Kun Wang Baisen Wu
}

Department of urology, Tongji Hospital, Huazhong University of Science and Technology, Wuhan, China

\section{Key Words}

Bladder cancer $•$ BDNF • BDNF Val66Met $・$ MiR-146b • CRK • Micro-vesicle

\begin{abstract}
Background/Aims: Emerging studies on brain-derived neurotrophic factor (BDNF) have shown that might be novel biomarkers and therapeutic targets for cancer. We explore the role of BDNF in the tumorigenesis of bladder cancer and the underlying molecular mechanism. Methods: 368 patients with diagnosed bladder cancer and 352 healthy controls were enrolled to evaluate the association of BDNF and the miR-146b. Bioinformatics algorithm analysis and luciferase assay were performed to identify the target genes of miR-146b. Real-time PCR and western-blot were carried out to validate the relationship between miR-146b and CRK. MTT assay and FACS were used to evaluated the proliferation and apoptosis of cancer cells. MVs were isolated and transfect into the culture cells to confirm the above observation. Results: The clinical study shows that BDNF Met/Met was significantly associated with the risk of bladder cancer. In addition, comparing with Val/Val and Val/Met, Met/Met has lower miR-146b level. Luciferase assay shows that BDNF Val/Val is apparently enhanced miR-146b promoterluciferase, but not BDNF Met/Met. Based on luciferase assay, CRK is a direct target gene of miR-146b. MiR-146b mimics significantly inhibited the expression of CRK and activation of AKT level. The expression of CRK and the activation of AKT (p-AKT) were significantly inhibited by MV-BDNF Val/Val-miR-146b or MV-BDNF Val/Met-miR-146b, but not MV-BDNF Met/Met-miR-146b. MV-BDNF Val/Val-miR-146b or Val/Met-miR-146b obviously inhibited cell proliferation, which eliminated by CRK. Meanwhile, with MV-BDNF Met/Met-miR-146b or Met/Met-miR-146b+CRK did not affect the proliferation. MV-BDNF Val/Val-miR-146b or $\mathrm{Val} /$ Met-miR-146b enhanced cell apoptosis, which could be eliminated by CRK. Meanwhile, MV-BDNF Met/Met-miR-146b or Met/Met-miR-146b+CRK did not promote apoptosis. Conclusion: BDNF VAL66MET polymorphism is associated with miR-146b and its target gene CRK. MiR-146b and CRK mediated BDNF VAL66MET polymorphism associated proliferation and apoptosis via activation of AKT. Thus, BDNF Val66Met is associated with the risk of bladder cancer, and the BDNF variant could be used a biomarker for the diagnosis of bladder cancer.
\end{abstract}

C. Li and X. Zeng contributed equally to this work. 


\section{Cellular Physiology Cell Physiol Biochem 2018;45:366-377 \\ and Biochemistry Published \begin{tabular}{l|l} 
DOI: 10.1159/000486908 & $\begin{array}{l}\text { (c) } 2018 \text { The Author(s). Published by S. Karger AG, Basel } \\
\text { www.karger.com/cpb }\end{array}$
\end{tabular} \\ Li et al.: BDNF Val66Met Polymorphism is Associated with Bladder Cancer Risk}

\section{Introduction}

As the $2^{\text {nd }}$ most common urological malignancy, bladder cancer contributes to $5 \%$ of deaths related to cancer and is responsible for healthcare costs as much as $\$ 4$ billion worldwide [1]. Men are four times more likely to develop the disease than women. The incidence in white men is twice higher than that in black men. Urothelial cell carcinoma (UCC) is the most common type, contributing to $90 \%$ of bladder cancers [2]. As natural biomaterials, micro-vehicles (MVs) seem to function as a carrier to transport bioactive molecules to target cells [3]. In addition, MVs can deliver oncolytic adenovirus or chemotherapeutic agents to tumor cells [4]. Interestingly, MVs themselves can also act as messengers to activate signaling pathways. It has been demonstrated that pre-instillation of MVs as natural biomaterials significantly increases the suppressant efficacy of intra-vesical chemotherapy on development and hematuria onset of orthotropic bladder cancer in mice, and MVs may function as an effective sensitizer for facilitating non-muscle-invasive bladder cancer (NMIBC) chemotherapy with unique clinical benefits [5].

MicroRNAs (miRNAs) plays a key role in posttranscriptional negative regulators in mRNA expression of the target genes [6]. A growing evidence has demonstrated that biological processes including tumor invasion pathways, Epithelial-mesenchymal transition (EMT), apoptosis avoidance, cell proliferation, organ development and angiogenic signaling are modulated by a variety of microRNAs [7]. Deregulated expression of miRNA has been observed in a variety of human tumors such as bladder tumor, and much proven data have revealed that some specific microRNAs could act as tumor suppressor genes or oncogenes [8]. Moreover, the first study of variant miRNA expression in bladder tumor presented in 2007 and found that upregulated urinary miRNAs and 10 miRNAs have been demonstrated to be clinically beneficial for diagnostics of noninvasive bladder cancer $[9,10]$. It has been shown that, following RNase treatment, MVs lost their transforming abilities revealing that RNAs in MVs accounts for, at least partially, the transformation to the malignancy [11]. It has been shown miR-146b-5p functioned as a critical regulator of NUMB and other genes to increase the transformation, and also triggered cell proliferation and genomic instability of the recipient cells, which will give significant insights into the leukemogenesis, and miR146b-5p within BCR-ABL1-positive MVs enhances leukemic transformation of hematopoietic cells [12].

Earlier reports demonstrated that overexpression of CRK in a variety of invasive cancers is related to tumor progression [13]. It has been demonstrated that CRK is a promising target at molecule level in aggressive bladder cancer on the basis of data from the present study [14]. Actually, CRK was upregulated in bladder cancer tissue specimens when compared with normal urothelium [14]. Simultaneous knockdown of CRK inhibited cell invasiveness, migration and proliferation, via a compromised HGF/c-Met feedback loop in two independent invasive bladder cancer cell lines [14].

One variant of BDNF has been reported to alter the enzymatic activity of the host gene, and over-expression of BDNF has been found to be associated with the tumorigenesis of bladder cancer $[15,16]$. It has also been shown that BDNF could promote the expression of miR-146 [17]. Using computational analysis, we found the CRK is a potential target gene of miR-146b, and CRK could facilitate the phosphorylation of AKT, which is an oncogene in bladder cancer [14]. Here, we isolated the MVs from human Wharton's jelly mesenchymal stem cells (hWJMSCs) from human umbilical cord, which has been reported to suppress the proliferation of bladder cancer cells, and examined the effect of the variant in BDNF on the expression of miR$146 \mathrm{~b}$ and its suppressive effect on the proliferation of bladder cancer cells [18].

\section{Materials and Methods}

\section{Sample collection}

A total of 368 patients with diagnosed bladder cancer and 352 controls were enrolled from our hospital, and the demographic parameters were comparable between the case and control groups, as shown 


\section{Cellular Physiology Cell Physiol Biochem 2018;45:366-377 \begin{tabular}{ll|l} 
DOI: 10.1159/000486908 & $\begin{array}{l}\text { O 2018 The Author(s). Published by S. Karger AG, Basel } \\
\text { www.karger.com/cpb }\end{array}$ \\
\hline
\end{tabular}}

Li et al.: BDNF Val66Met Polymorphism is Associated with Bladder Cancer Risk

in Table $1.5 \mathrm{ml}$ of peripheral blood were collected from each participant after written consent was provided, and Ethics Committee of the Hospital of our institution has approved the protocol of the study.

Human umbilical cord collection

Human umbilical cord tissues were collected from 10 full-term healthy pregnant women from our institute. All of the samples were stored in liquid nitrogen. Cellular isolation was started within 4 hour after partum. Ethics Committee of the Hospital of our institution has approved the protocol of the study and written informed consents were obtained from all participants prior to the study. The patients have already signed informed consent for participation in the study.

\section{The hWJMSCs isolation}

Cold Dulbecco's modified Eagle medium (DMEM) was utilized to store umbilical cords aseptically, and cellular isolation was began within 4 hour after partum. Firstly, removed blood cells from the vein and arteries, pulverized the umbilical cord into 1-2 $\mathrm{mm}^{3}$ pieces approximately. Petri dish with DMEM supplemented with low glucose (DMED-LG, Gibco) and 10\% fetal bovine serum (FBS, Gibco) was utilized to maintain the cord pieces under an atmosphere with $5 \% \mathrm{CO}_{2}$ at $37^{\circ} \mathrm{C}$ Then the fresh medium was replaced the old medium every two days. $0.25 \%$ trypsin (Gibco) was utilized to collect the adherent cells after two weeks. Only cells between passage 3 and 6 were used for research. Three independent experiments were carried out.

\section{Isolation of $M V S$}

Briefly, DMEM contained 0.5\% BSA (bovine serum albumin) (Sigma-Aldrich, St. Louis, MO) and deprived of FBS was utilized to incubate hWJMSCs for 12 hours. RPMI-1640 with 0.5\% BSA and without serum was utilized to maintain HFFs. Trypan blue exclusion was utilized to detect viability of hWJMSCs (99\%) and HHFs (90\%), and TUNEL assay was performed to detect apoptosis of hWJMSCs (0\%) and HHFs (3\%). Then the cells were subjected to centrifugation for 20 minutes at 2, $000 \mathrm{~g}$ for decontamination, next the cell-free supernatants were subjected to ultracentrifuge at $4^{\circ} \mathrm{C}$ for $60 \mathrm{~min}$ at $100,000 \mathrm{~g}$ in a SW41 swing rotor (Beckman Coulter Optima L-80K ultracentrifuge; Beckman Coulter, Fullerton, CA). Serum-free M199 (Sigma-Aldrich) supplemented with 25 mM HEPES was utilized to wash the MVs, then subjected to ultracentrifuge at $4^{\circ} \mathrm{C}$ for $60 \mathrm{~min}$ at 100, $000 \mathrm{~g}$. Serum-free M199 (Sigma-Aldrich) was utilized to suspend MV pellets, and Bradford assay (Bradford protein assay kit, P0006, beyotime institute of biotechnology) was utilized to quantify protein content. Limulus test (Charles River Laboratories, Inc., Wilmington, MA, USA) was utilized to exclude Endotoxin contaminations of MVs following supplier's recommendation. Three independent experiments were carried out.

Taqman

The TaqMan methodology $(\mathrm{AB}$, foster city, $\mathrm{CA})$ was utilized to analyze the genotype of the SNP (BDNF VAL66MET) based on the instructions of the supplier.

\section{MiRNA isolation and real-time PCR}

TRIzol reagent (Invitrogen, Carlsbad, CA, USA) was utilized to extract total RNA following standard protocol indicated by manufacturer. Bio Photometer plus (Eppendorf AG, Hamburger, Germany) was utilized to check the quality and quantify RNA extracted. For detection of CRK, ReverTra Ace qPCR RT Kit (TOYOBO, Osaka, Japan) was utilized to synthesize cDNA with $1 \mathrm{mg}$ total RNA. In order to detect miR- 


\section{Cellular Physiology Cell Physiol Biochem 2018;45:366-377 \begin{tabular}{c|c|c|c|} 
DOI: 10.1159/000486908 & O 2018 The Author(s). Published by S. Karger AG, Basel \\
www.karger.com/cpb
\end{tabular}}

Li et al.: BDNF Val66Met Polymorphism is Associated with Bladder Cancer Risk

146b, M-MLV reverse transcriptase (Invitrogen, Carlsbad, CA) with specific reverse transcription primer (RiboBio, Guangzhou, China) were utilized to reverse transcribe RNA following supplier's instruction. ABI 7500 real-time PCR system (Applied Biosystems, Foster city, USA) contained Real time PCR Master mix kit (TOYOBO, Osaka, Japan) was utilized to perform real-time quantitative PCR to quantify miR-146b and CRK expression levels. U6 was served as internal reference gene, and reaction were run at $9^{\circ} \mathrm{C}$ for $60 \mathrm{~s}$ for initial denaturation, followed by 48 cycles of $9^{\circ} \mathrm{C}$ for $15 \mathrm{~s}, 6^{\circ} \mathrm{C}$ for $30 \mathrm{~s}, 72^{\circ} \mathrm{C}$ for $45 \mathrm{~s} .2^{-\Delta \Delta C \mathrm{~T}}$ method was utilized to calculate the expressions of miR-146b and CRK mRNA. All reactions were performed in triplicate.

\section{Cell culture and transfection}

RPMI 1640 medium (GIBCO®, Life Technologies, Carlsbad, CA, USA) contained $100 \mathrm{mg} / \mathrm{mL}$ ampicillin and 10\% FBS (fetal bovine serum) was utilized to maintain the T24 AND RT4 cells in an incubator with 5\% $\mathrm{CO}_{2}$ at $3^{\circ} \mathrm{C}$. Lipofectamine 2000 (Invitrogen, USA) was utilized to transfect the cells with MVs of different genotype, miR-146b mimic, CRK at a final concentration of $50 \mathrm{nM}$. All tests were performed three times.

\section{Cell proliferation}

T24 and RT4 cells were cultured into 48-well plates at a final concentration of $2.5 \times 10^{3}$ cell/well, after the cells attached for 6 hours, RPMI1640 medium was utilized to replace the medium, and incubated for 72 hours. CCK-8assay kit (Dojindo Molecular Technologies, Inc., Kumamoto, Japan) was utilized to determine cell proliferation 48 hours after transfection based on supplier's guideline. Synergy ${ }^{\text {TM }} 2$ MultiMode Microplate Reader (BioTek Instruments, Inc., headquartered in Winooski, VT, USA) was utilized to determine absorbance value (A) at $450 \mathrm{~nm}$. All experiments were performed three times.

\section{Luciferase assay and Vector construction (miR-146b promoter+BDNF)}

Briefly, PCR was carried out to amplify full promoter region of miR-146b from DNA templates isolated from samples that collected from subjects. BDNF coding sequence contained VAL/VAL was amplified. Then the PCR products were sub-cloned into pGL3-basic vector (Promega, MD, USA). A firefly gene, as reporter, was inserted into the downstream of miR-146b promoter. In the vector containing BDNF VAL/VAL, site-directed mutagenesis kit was used to introduce the VAL66MET polymorphism, with one vector containing BDNF VAL/VAL and the other vector containing BDNF MET/MET. The Lipofectamine 2000 (Invitrogen, Carlsbad, CA, USA) was utilized to transfect the cells with BDNF (VAL/VAL or MET/MET) or the vector containing the promoter of miR-146b following manufacturer's recommendation. 48 hours after transfection, A Beckman Coulter LD400 luminometer (Beckman, Fullerton, CA) and Dual-Glo substrate system (Promega, Madison, WI, USA) were utilized to measure luciferase activity 48 hours after transfection. Experimental data was shown as the ratio of Renilla luciferase/ Firefly luciferase. Each test was carried out three times.

\section{Luciferase assay and Vector construction (miR-146b and target 3UTR)}

The whole sequence of CRK 3'UTR with miR-146b binding sites was amplified using PCR, and the full fragment CRK 3'UTR was sub-cloned into psi-CHECK2 luciferase reporter vector (Promega, Madison, WI, USA) downstream of firefly luciferase, and site-directed mutagenesis kit was used to generate CRK-3'UTR and CRK-Mut-3'UTR respectively. Then the cells were co-transfected with miR-146b mimic/NC (negative control) and reporter constructs containing either wild-type or mutant CRK 3'UTR by lipofectamine 2000 (Invitrogen, CA, USA) following manufacturer's recommendation. 48 hours after transfection, A Beckman Coulter LD400 luminometer (Beckman, Fullerton, CA) and Dual-Glo substrate system (Promega, Madison, WI, USA) were utilized to measure luciferase activity 48 hours after transfection. Experimental data was shown as the ratio of Renilla luciferase/ Firefly luciferase. Each test was carried out three times.

\section{Western blot analysis}

Lysis buffer contained $150 \mathrm{mM} \mathrm{NaCl}, 1 \mathrm{mM}$ EDTA, $50 \mathrm{mM}$ Tris (pH 8) 0.25\% sodium deoxycholate, $0.1 \%$ Triton X-100 and protease inhibitor cocktail (Roche, Rotkreuz, Switzerland) was utilized to extract whole cells protein for western-blot analysis. 10\% SDS-PAGE was utilized to resolve protein samples, and then the gels electro-transferred onto a nitrocellulose membranes (GE Healthcare, Little Chalfont, UK), and $5 \%$ non-fat milk was utilized to block the membrane at room temperature for $60 \mathrm{~min}$, and primary antibodies against CRK at a dilution of 1:2000 (Sigma-Aldrich, St. Louis, MO, USA), primary antibodies Against AKT at a dilution of 1:1000 (Sigma-Aldrich, St. Louis, MO, USA), primary antibody against p-AKT at a 


\section{Cellular Physiology Cell Physiol Biochem 2018;45:366-377 \begin{tabular}{l|l|l} 
and Biochemistry Published 10.1159/000486908 & $\begin{array}{l}\text { (c) } 2018 \text { The Author(s). Published by S. Karger AG, Basel } \\
\text { www.karger.com/cpb }\end{array}$
\end{tabular} \\ Li et al.: BDNF Val66Met Polymorphism is Associated with Bladder Cancer Risk}

dilution of 1:2000 (Sigma-Aldrich, St. Louis, MO, USA) and specific b-actin at a dilution of 1:10000 (AbCam, Cambridge, MA, USA) were utilized to incubate the membrane at $4^{\circ} \mathrm{C}$ for 12 hours, subsequently HRP (horseradish peroxidase)-linked secondary antibody at a dilution of 1:12000 (Dako, Glostrup, Denmark) was utilized to detect signals at room temperature for $90 \mathrm{~min}$. An enhanced chemiluminescence system (ECL; GE Healthcare) was utilized to visualize the blot in accordance with manufacturer's recommendation, and ImageJ software (http://rsb.info.nih.gov/ij/) was utilized to quantify relative intensity of the target bands. Each experiment was run three times.

\section{Cell apoptosis}

FITC Annexin V Apoptosis Detection Kit contained PI (Bio Legend, San Diego, CA) was utilized to perform cell apoptosis assay. Cold Cell Staining Buffer (Bio Legend, San Diego, CA) was utilized to wash the cells twice, Annexin V Binding Buffer (Bio Legend, San Diego, CA) was utilized to re-suspend the cells at a final concentration of $5 \times 10^{6}$ cells per well, $10 \mu \mathrm{L}$ propidiumiodide and $5 \mu \mathrm{L}$ of FITC Annexin V (Biolegend, San Diego, CA) was utilized to stain the cells, and incubated at room temperature for 15 min in darkness. FACSCalibur flow cytometer (BD Biosciences, New Jersey, USA) were utilized to evaluate the apoptosis of T24 AND RT4 cells. Three independent experiments were carried out.

\section{Statistical analysis}

SPSS version 17.0 (SPSS, Chicago, IL, USA), GraphPad Prism software (GraphPad, La Jolla, CA, USA) and Microsoft excel (Microsoft Corporation., Redmond, Washington, US) were utilized to perform all statistical analysis. Kruskal-Wallis test, Mann-Whitney U test and Student's t-test was utilized to calculate obvious differences among independent groups. The value of P less than 0.05 was considered statistically significant.

\section{Results}

BDNF Val66Met polymorphism is associated with the risk of bladder cancer

To study the association between the BDNF Val66Met polymorphism and the risk of bladder cancer, 368 patients with diagnosed bladder cancer and 352 controls were enrolled in this study, and the demographic parameters were comparable between the case and control groups, as shown in Table 1. Furthermore, the genotypic and allelic frequencies of BDNF Val66Met polymorphism were determined and compared between the case and control groups. Comparing with Val/Val and Val/Met, Met/Met was significantly associated with the risk of bladder cancer (as shown in Table 2).

The BDNF Val66Met polymorphism regulates the transcription activity of miR-164b

The effect of BDNF Val66Met polymorphism upon the transcription activity of the miR-146b promoter was examined using luciferase assay. In Fig. $1 \mathrm{~A}$, we showed the variant located in the coding region of BDNF, and it possible effect on the promoter of miR-146b. We constructed the vectors containing either BDNF Val/Val or Met/Met, and vectors containing the promoter of miR-146b with a downstream firefly luciferase reporter gene. As shown in Fig. 1B, luciferase activity of cells apparently up-regulated following the transfection with vectors containing BDNF Val/Val compared with the control, while luciferase activity of cells transfected
Table 2. Genotypic and allelic frequency of the participants enrolled in this study

\begin{tabular}{|c|c|c|c|}
\hline Genotype & $\begin{array}{l}\text { Bladder cancer } \\
\qquad \mathrm{N}=368\end{array}$ & $\begin{array}{l}\text { Control } \\
\mathrm{N}=352\end{array}$ & Odds ratio and $P$ value \\
\hline \multicolumn{4}{|l|}{ Val66Met } \\
\hline \multicolumn{4}{|l|}{ Genotype } \\
\hline $\mathrm{Val} / \mathrm{Val}$ & $98(26.6)$ & $82(23.3)$ & \\
\hline Val/Met & $201(54.6) 1$ & $177(50.3)$ & $1.05(0.74-1.50) \mathrm{P}=0.7786$ \\
\hline $\begin{array}{l}\text { Met/Me } \\
t\end{array}$ & $69(18.8)$ & $93(26.4)$ & $1.61(1.05-2.47) \mathrm{P}=0.0290$ \\
\hline \multicolumn{4}{|l|}{ Allele } \\
\hline Val & $397(53.9) 3$ & $341(48.4)$ & $1.24(1.01-1.53) \mathrm{P}=0.0369$ \\
\hline Met & $339(46.1) 3$ & $363(51.6)$ & \\
\hline
\end{tabular}




\section{Cellular Physiology Cell Physiol Biochem 2018;45:366-377

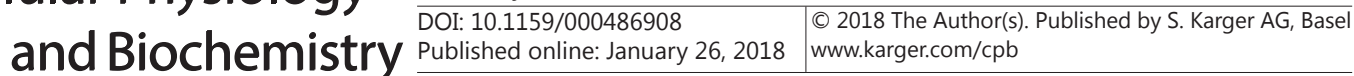

Fig. 1. A: The variant located in the coding region of BDNF. B: Luciferase activity of cells was apparently upregulated subsequent to transfect with vectors containing BDNF Val/Val compared with the control

with vectors containing BDNF Met/Met was substantially attenuated compared with vectors containing BDNF Val/Val, suggesting that the BDNF Val66Met polymorphism regulates the transcription activity of miR-146b.

\section{CRK is a virtual target gene of miR-146b}

Bioinformatics algorithm analysis was performed to explore the target gene of miR-146b. As shown in Fig. 2, CRK, IGFBP5, RASGRP1 and THFAIP8 were identified as miR146b target genes with binding sites located in 3'UTR. In addition, we found that luciferase activity of wild-type CRK 3'UTR was apparently reduced subsequent to transfection with miR-146b compared to that in control, but the luciferase activity of mutant CRK 3'UTR and control showed no obvious difference (Fig. 2A). As shown in Fig. 2B, miR-146b might also target IGFBP5 through bind IGFBP5 3'UTR, whereas the luciferase activity of wild-type and mutant IGFBP5 3'UTR was comparable with control following introduction of miR-146b. Similarly, RASGRP1 was identified as a protential miR-146b target gene with a binding site located within 3'UTR of CRK, but the luciferase activities of wild-type and mutant RASGRP1 3'UTR were similar with control after transfection with miR146b (Fig. 2C). MiR-146b might bind THFAIP8 3'UTR and regulate it expression, while luciferase activities of wild-type and mutant THFAIP8 3'UTR were

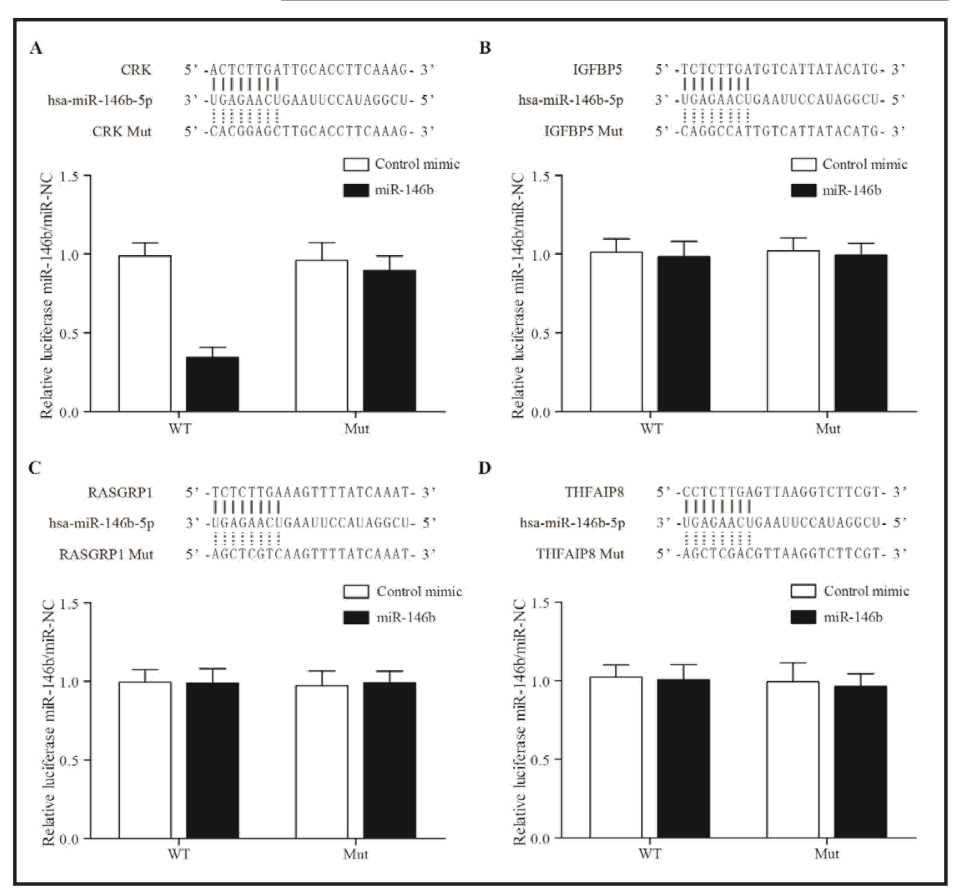

Fig. 2. A: MiR-146b might target CRK through bind to CRK 3'UTR, and miR-146b significantly suppressed luciferase activity of wild-type CRK 3'UTR, but not that of mutant CRK 3'UTR. B: MiR-146b might target IGFBP5 via binding to IGFBP5 3'UTR, and miR-146b didn't affect luciferase activity of wild-type and mutant IGFBP53'UTR. C: MiR-146b might target RASGRP1 via binding to RASGRP1 3'UTR, and miR-146b didn't affect luciferase activity of wild-type and mutant RASGRP1 3'UTR. D: MiR-146b might target THFAIP8 through bind to THFAIP8 3'UTR, and miR-146b didn't affect luciferase activity of wild-type and mutant THFAIP8 3'UTR

similar with control after transfection with miR-146b (Fig. 2D). These results indicated that CRK is a virtual target gene of miR-146b with a binding site located within CRK 3'UTR. 
MiR-146b inhibits CRK expression

To examine if miR-146b regulates expression of CRK, IGFBP5, RASGRP1 or THFAIP8 in cultured cells, miR-146b mimics were transfected into T24 and RT4 cells. The expression of CRK, IGFBP5, RASGRP1 and THFAIP8 were determined. MiR-146b mimics significantly inhibit the expression of CRK (Fig. 3A). However, the expression of IGFBP5 (Fig. 3B), RASGRP1 (Fig. 3C) and THFAIP8 (Fig. 3D) were not regulated by miR-146b mimics in T24 and RT4 cells. These results confirmed that miR146b inhibit the expression of CRK, but not IGFBP5, RASGRP1 and THFAIP8 in T24 or RT4 cells.

The expression of miR$146 b$ and CRK in associated with BDNF Val66Met polymorphism

Furthermore, MVs were isolated form umbilical cord blood vessel derived from subjects genotyped as $\mathrm{Val} / \mathrm{Val}$, Val/Met or Met/Met following the protocol described in the methods section. As shown in Fig. 4A, miR-146b level was comparable in $\mathrm{Val} / \mathrm{Val}$ and Val/Met, and both were substantially higher than Met/Met. The expression of CRK was detected in T24 and RT4 cells transfected with MVs isolated form umbilical cord blood genotyped as $\mathrm{Val} / \mathrm{Val}$, Val/Met and Met/Met. The mRNA and protein levels of CRK in T24 and RT4 cells were significantly decreased subsequent to transfect with MVBDNF Val/Val-miR-146b

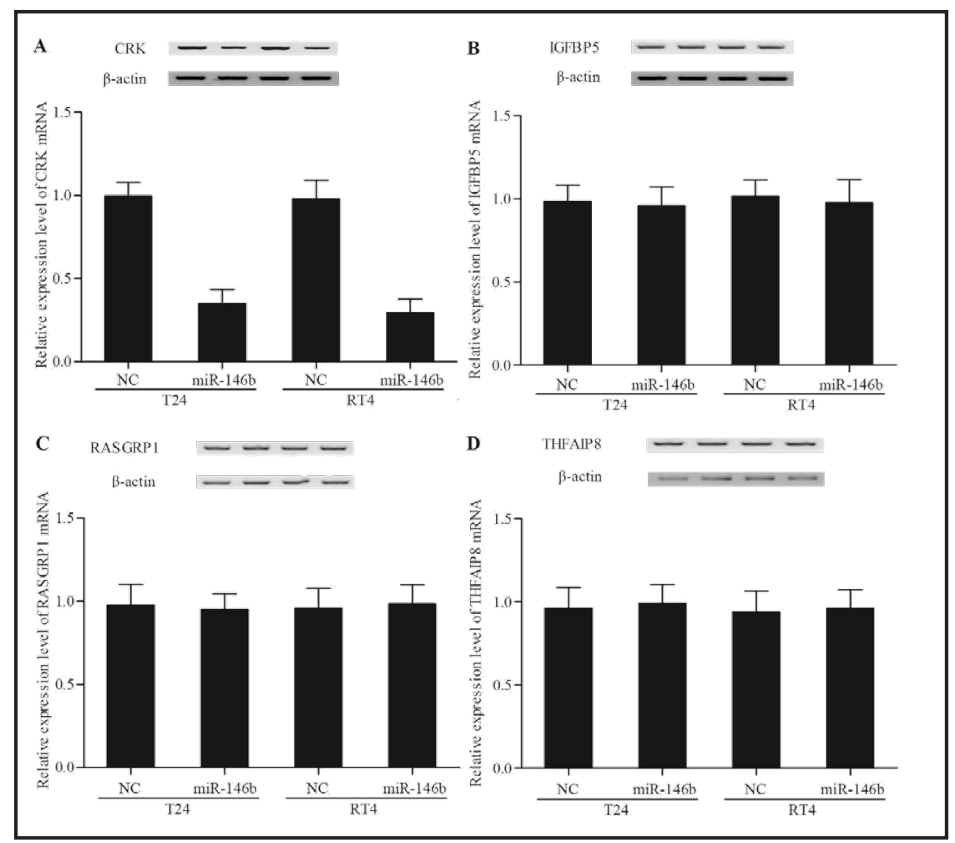

Fig. 3. A: MiR-146b significantly suppressed $C R K$ and $p-A K T$ expressions, but not AKT level in T24 and RT4 cells. B: MiR-146b had no effect on levels of IGFBP5, p-AKT and AKT in T24 and RT4 cells. C: MiR-146b had no effect on levels of RASGRP1, p-AKT and AKT in T24 and RT4 cells. D: MiR-146b had no effect on levels of THFAIP8, p-AKT and AKT in T24 and RT4 cells

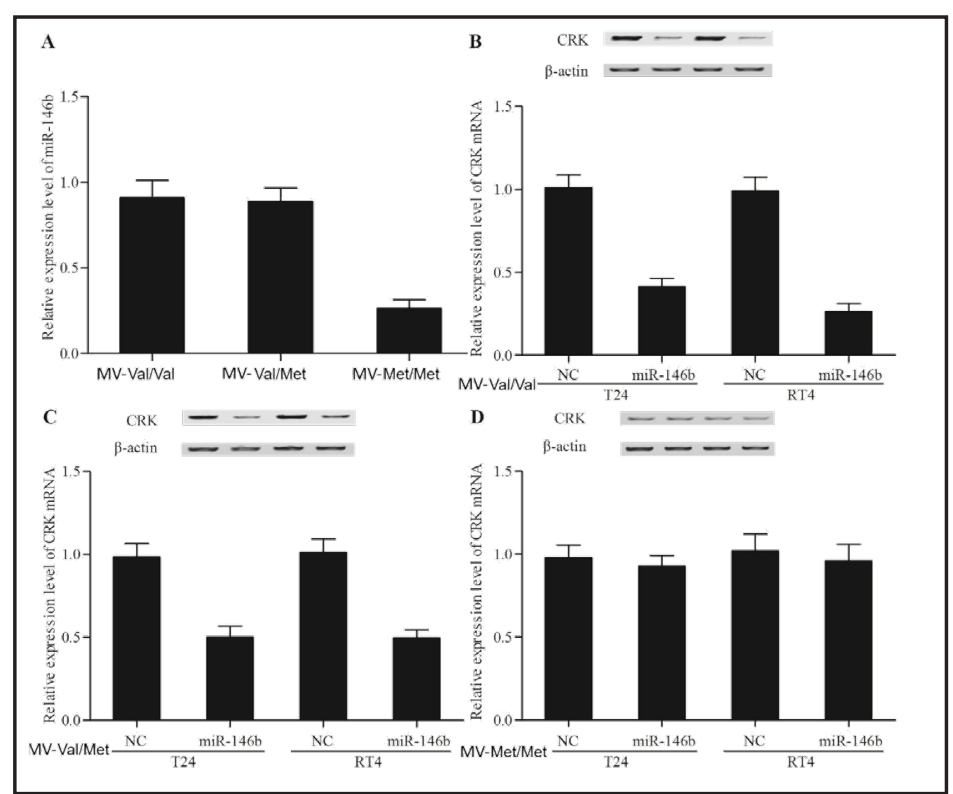

Fig. 4. A: Val/Val group showed a higher level of miR-146b. B: CRK and p-AKT levels in T24 and RT4 cells were significantly down-regulated when transfected with MV-BDNF Val/Val-miR-146b. C: CRK and p-AKT levels in T24 and RT4 cells were significantly down-regulated when transfected with MV-BDNF Val/Met-miR-146b. D: CRK, AKT and p-AKT levels in T24 and RT4 cells transfected with MV-BDNF Met/Met-miR146b showed no obvious difference with those of NC group 
(Fig. 4B) or MVBDNF Val/MetmiR-146b (Fig. 4C) compared with NC control. Whereas levels of CRK mRNA and protein in T24 and RT4 cells transfected with MV-BDNF Met/Met-miR146b (Fig. 4D) were similar in both groups.

BDNF Val66Met polymorphism regulates the proliferation and apoptosis of T24 and RT4 cells

We also examined proliferation and apoptosis of T24 and RT4 cells transfected with MVs isolated form umbilical cord blood genotyped as Val/Val, Val/Met and Met/Met and the rescue test was also performed by overexpression CRK in miR146b overexpressed cells. As shown in Fig. 5, MV-BDNF Val/ Val-miR-146b (Fig. 5A) or MV-BDNF Val/ Met-miR-146b (Fig. 5B) significantly suppressed growth rate of T24 and RT4 cells compared to those of NC group, but treating with CRK attenu-

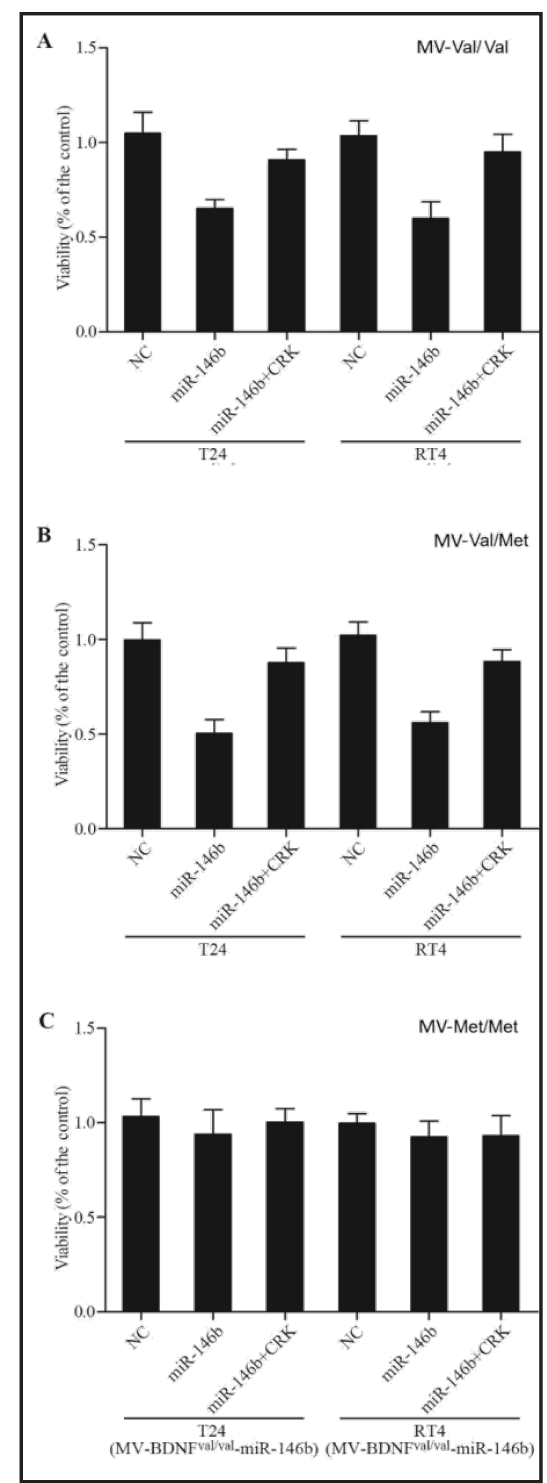

Fig. 5. Viability was determined in the of bladder cancer cells treated with control, miR-146b collected from individuals of different genotype and miR-146+CRK. A: MV-BDNF Val/ Val-miR-146b significantly reduced T24 and RT4 cells growth rate, CRK abolished inhibition effect of MV-BDNF Val/Val-miR-146b. B: MV-BDNF Met/ Val-miR-146b significantly reduced T24 and RT4 cells proliferation, CRK abolished inhibition effect of MV-BDNF Val/Val-miR-146b. C: MV-BDNF Met/ Met-miR-146b and MV-BDNF Met/MetmiR-146b+CRK had no effect on growth rate of T24 and RT 4 cells.
Fig. 6. Apoptosis was determined in the of bladder cancer cells treated with control, miR-146b collected from individuals of different genotype and miR-146+CRK. A: MV-BDNF Val/ValmiR-146b significantly up-regulated T24 and RT4 cells apoptosis, CRK abolished promotion effect of MV-BDNF Val/ValmiR-146b. B: MV-BDNF Met/Val-miR$146 \mathrm{~b}$ significantly up-regulated T24 and RT4 cells apoptosis, CRK abolished promotion effect of MV-BDNF Val/ Val-miR-146b. C: MV-BDNF Met/MetmiR-146b and MV-BDNF Met/Met-miR$146 b+C R K$ had no effect on T24 and RT4 cells apoptosis.

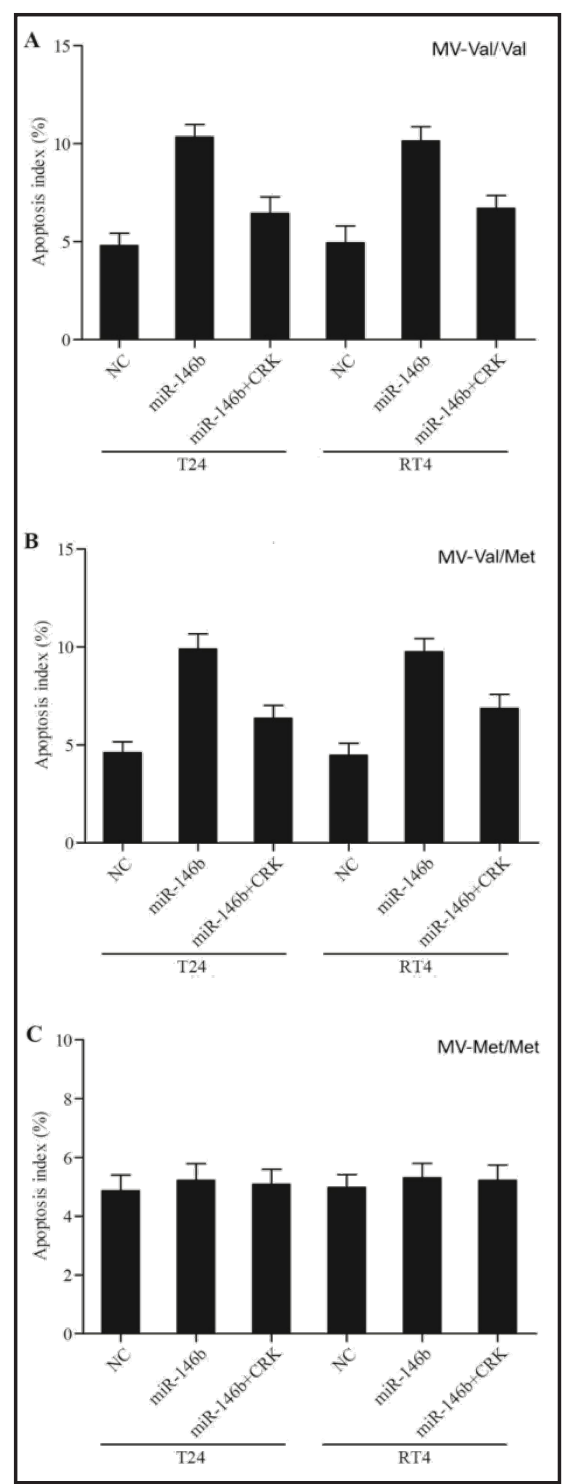


ated the inhibitory effect of MV-BDNF Val/ Val-miR-146b (Fig. 5A) or MV-BDNF Val/ Met-miR-146b (Fig. 5B) in T24 and RT4 cells. While the cells treated with MV-BDNF Met/Met-miR-146b or MV-BDNF Met/MetmiR-146b+CRK displayed a similar viability of T24 and RT4 with NC group (Fig. 5C). Meanwhile, MV-BDNF Val/Val-miR-146b (Fig. 6A) or MV-BDNF Val/Met-miR-146b (Fig. 6B) significantly promoted survival of T24 and RT4 cells compared with those of NC group, but treating with CRK attenuated the promotion effect of MV-BDNF Val/ValmiR-146b (Fig. 6A) or MV-BDNF Val/MetmiR-146b (Fig. 6B) in T24 and RT4 cells, while cells treated with MV-BDNF Met/ Met-miR-146b or MV-BDNF Met/Met-miR146b+CRK exhibited a comparable growth rate of T24 and RT4 with NC group (Fig. 6C).

MVs collected from individuals of different genotypes regulates the activation of AKT, but not the expression of $A K T$

To further explore the mechanism underlying, the protein and phosphorylation levels of AKT were determined in the culture cells treated with MVs of different genotype. As shown in Fig. 7, the protein expression of AKT was all comparable among all differently treated group as well as the control group. While the introduction

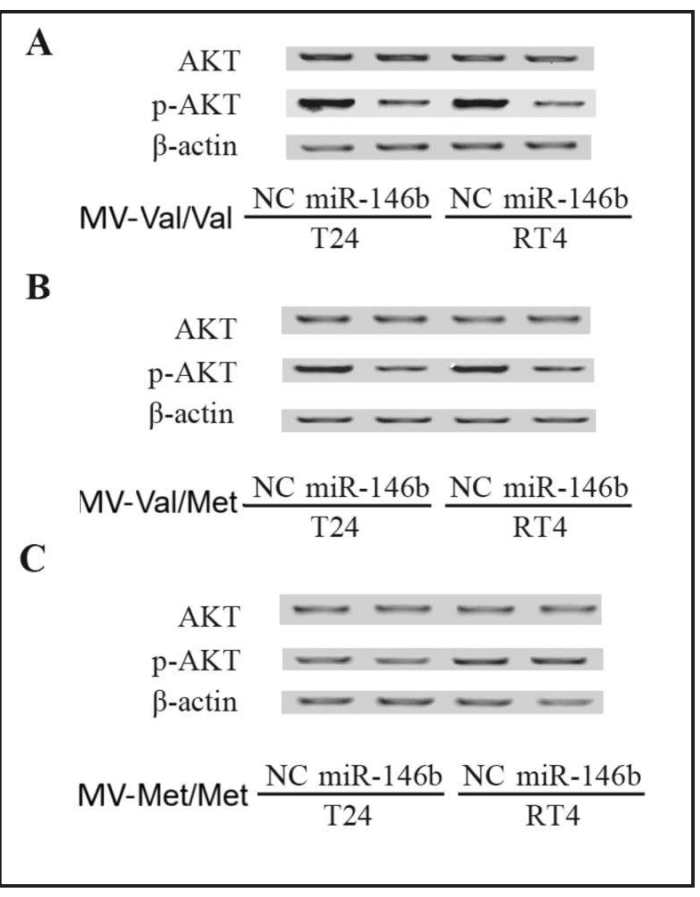

Fig. 7. Protein expression of AKT and p-AKT were determined in the of bladder cancer cells treated with control, miR-146b collected from individuals of different genotype and miR-146+CRK. A: MV-BDNF Val/Val-miR-146b significantly down-regulated p-AKT but not total AKT in T24 and RT4 cells. B: MV-BDNF Met/Val-miR-146b significantly downregulated p-AKT but not total AKT in T24 and RT4 cells. C: MV-BDNF Met/Met-miR-146b neither downregulated p-AKT nor total AKT in T24 and RT4 cells of miR-146b carried by MVs collected from individuals of Val/Val or Val/Met substantially suppressed the activation level of AKT, but the MVs genotyped as Met/Met had minimal effect on the activation level of AKT.

\section{Discussion}

As plasma membrane-derived particles, MVs are produced from cells through plasma membrane's outward budding and fission [19]. MVs have fundamental pathological / physiological roles, such as the advancement of the tumor through the regulation of tumor metastasis, angiogenesis, immune inhibition and tumor-stroma interactions [20]. Tumor cells fundamentally release MVs when they transmit their metastasis-related proteases, receptors of membrane growth factor and other molecules with bioactivity to other tissue components, nontumor cells and other tumor cells in the tumor microenvironment, hence enhancing tumor progression [21]. It has been shown that MVs shedding is a main pathway for secretion of a metastasis-related protease known as cathepsin B, which is released from tumor cells [22]. Studies with human and murine lung cancer cells have demonstrated that the expression of several pro-angiopoietic factors are induced by MVs shed by tumor cells in stromal cells, hence playing an active regulatory role in the behavior of tumor stroma and endothelium [22]. Tumor-derived MVs are abundant in proteases correlated with metastasis, including matrix metalloproteinase (MMP)-2 and MMP-9, which are associated with the degradation of extracellular matrix in the tumor microenvironment, 
Hence enhancing tumor metastasis [23]. The number of MVs shed by tumor cells have been shown to be related to the invasive ability of tumor cells either in vivo or in vitro [24]. In more recent study, miRNAs have been reported to be involved in cancer occurrence and progression, functioning either as tumor oncogenes or suppressors [25]. Intriguingly, recent reports have shown an association between cancer pathogenesis and miRNA expression for an array of cancer [26]. In bladder tumors or in other cancers, deregulation of a wide range of miRNAs (miR-146b, miR-182, miR-200b and miR-204, miR-145, miR-143, miR-138, miR$133 b, m i R-133 a, m i R-9, m i R-1)$ has been previously observed [27, 28]. And deregulation of $m i R-146 b$ was considered to be specific in bladder cancer [27]. Using computational analysis and luciferase assay, we screened several possible candidate target genes of miR-146b, and identified CRK as a direct target of miR-146b.

BDNF gene, causing replacement of a valine by a methionine (Val66Met), results in interrupted delivery of either the protein or mRNA to terminals of neuron and decreased release of BDNF protein dependent on activity either in vivo or in vitro [29]. Val66Met SNP is a human-specific frequent genetic variant [30]. Val66Met SNP has been related to decreased volume of prefrontal and hippocampal cortical gray matter and changed performance in memory tasks [31]. Studies in vitro neuronal cultures have demonstrated an effect of BDNF in regulation of miRNA levels, indicating that the functions of natural variant at the BDNF locus may be triggered via alterations in miRNA levels [32]. Val66Met impacts the levels of miRNAs more likely through regulating BDNF-dependent transcription factor binding in regulatory regions rather than through miRNA biogenesis [33]. Among the influenced miRNAs, miR$146 \mathrm{~b}$ and its regulated downstream targets, which are especially rich in neuronal genes, seem to have significant attribution to the biological properties of the Val66Met variant, and lowered levels of miR-146b, resulted in elevated Irak1 protein levels and higher Per1 and Npas4 mRNA levels in vitro and are related to similar alterations in the hippocampus of hBDNF ${ }^{\text {Met/Met }}$ mice [17]. In line with this, we performed the luciferase assay to test the effect of BDNF of different genotypes on the transcription of miR-146b promoter, and found that homogenous Met allele significantly undermined the transcription of miR-146b promoter. Furthermore, we collected MVs from individuals of different genotypes, and found that Val/ Val and Val/Met were comparable with each other, and both were substantially higher than that of Met/Met.

The signaling adaptor protein CRK was primarily separated from an avian sarcoma CT10 retrovirus as an oncogene fusion product [34]. Its homologs in mammalian are consisted of CRK-I, CRK-II, and CRK-L (CRK-like). CRK-II has an additional SH3 domain while CRK-I has an SH2 and an SH3 domain. Increased concentrations of CRK mRNAs and the protein are related to the possibility of malignancy of a variety of tumors in human, such as breast tumors, glioblastoma, synovial sarcoma and ovarian tumors [13]. CRK facilitates EMT and is necessary for cell spreading mediated by HGF in epithelial cells of kidney [35]. Previously, we have demonstrated that CRK is necessary for persistent phosphorylation of the SH2 domain binding protein Gab1 responding to HGF stimulation, and the subsequent downstream Rac1 activation in synovial sarcoma cells [36]. These reports indicate that CRK has the possibility to regulate EMT via growth factors such as HGF. It has been demonstrated that the PI3K-AKT pathway acts as an important mediator of CRK-triggered oncogenesis. It is well demonstrated that the stimulation of the AKT pathway offers a survival signal in a lot of circumstances including inhibition of apoptosis, attachment to the extracellular matrix and growth factor stimulation [37]. Hence, it is plausible that CRK enhances anchorage-independent growth by producing a survival signal via the underlying stimulation of the AKT pathway [12]. In this study, we transfected the bladder cancer cells with those MVs collected from the individuals genotyped as Val/Val, Val/Met and Met/Met, and detected miR-146b, CRK mRNA and protein, p-AKT levels among above three groups, and found that Val/Val group showed a higher level of miR-146b, while CRK and p-AKT levels were remarkably repressed after transfecting with MV-BDNF Val/Val-miR-146b or MV-BDNF Val/Met-miR-146b, while notably up-regulated subsequent to transfect with MV-BDNF Val/Met-miR-146b. 


\section{Cellular Physiology Cell Physiol Biochem 2018;45:366-377 and Biochemistry Published \begin{tabular}{l|l} 
DOI: 10.1159/000486908 & $\begin{array}{l}\text { (c) } 2018 \text { The Author(s). Published by S. Karger AG, Basel } \\
\text { www.karger.com/cpb }\end{array}$
\end{tabular}}

Li et al.: BDNF Val66Met Polymorphism is Associated with Bladder Cancer Risk

\section{Conclusion}

In summary, our results demonstrate the BDNF val66met polymorphism is associated with risk of bladder cancer. In our study, we validated that BDNF Val66Met Polymorphism is significantly influenced the miR-146b levels in MVs, and then its direct target gene CRK. As CRK is an Key kinase influencing the phosphorylation of AKT, BDNF Val66Met Polymorphism regulates the apoptosis and proliferation of bladder cancer cells via miR146b and CRK-AKT pathway.

\section{Abbreviations}

BDNF (Brain-derived neurotrophic factor); MVs (Micro-vechicles); UCC (Urothelial cell carcinoma); AKT (RAC-alpha serine/threonine-protein kinase); CRK (CRK Proto-Oncogene); hWJ-MSCs (human Wharton's jelly mesenchymal stem cells)

\section{Disclosure Statement}

The authors have nothing to disclose.

\section{References}

1 Simons MP, Nauseef WM, Griffith TS: Neutrophils and TRAIL: insights into BCG immunotherapy for bladder cancer. Immunol Res 2007;39:79-93.

2 Rossi R, Lichtner M, Iori F, Ermocida A, Mascia C, Mengoni F, Sauzullo I, Dini D, Mastroianni CM, Vullo V: Dendritic cells in blood and urine samples from bladder cancer patients undergoing BCG immunotherapy. Arch Ital Urol Androl 2013;85:157-163.

-3 Mause SF, Weber C: Microparticles: protagonists of a novel communication network for intercellular information exchange. Circ Res 2010;107:1047-1057.

4 Ran L, Tan X, Li Y, Zhang H, Ma R, Ji T, Dong W, Tong T, Liu Y, Chen D, Yin X, Liang X, Tang K, Ma J, Zhang Y, Cao X, Hu Z, Qin X, Huang B: Delivery of oncolytic adenovirus into the nucleus of tumorigenic cells by tumor microparticles for virotherapy. Biomaterials 2016;89:56-66.

5 Jin X, Ma J, Liang X, Tang K, Liu Y, Yin X, Zhang Y, Zhang H, Xu P, Chen D, Zhang T, Lu J, Hu Z, Qin X, Zeng X, Li L, Huang B: Pre-instillation of tumor microparticles enhances intravesical chemotherapy of nonmuscleinvasive bladder cancer through a lysosomal pathway. Biomaterials 2017;113:93-104.

6 Ambros V: The functions of animal microRNAs. Nature 2004;431:350-355.

-7 Suarez Y, Fernandez-Hernando C, Yu J, Gerber SA, Harrison KD, Pober JS, Iruela-Arispe ML, Merkenschlager M, Sessa WC: Dicer-dependent endothelial microRNAs are necessary for postnatal angiogenesis. Proc Natl Acad Sci U S A 2008;105:14082-14087.

8 Yu G, Yao W, Xiao W, Li H, Xu H, Lang B: MicroRNA-34a functions as an anti-metastatic microRNA and suppresses angiogenesis in bladder cancer by directly targeting CD44. J Exp Clin Cancer Res 2014;33:779.

-9 Gottardo F, Liu CG, Ferracin M, Calin GA, Fassan M, Bassi P, Sevignani C, Byrne D, Negrini M, Pagano F, Gomella LG, Croce CM, Baffa R: Micro-RNA profiling in kidney and bladder cancers. Urol Oncol 2007;25:387-392.

10 Puerta-Gil P, Garcia-Baquero R, Jia AY, Ocana S, Alvarez-Mugica M, Alvarez-Ossorio JL, Cordon-Cardo C, Cava F, Sanchez-Carbayo M: miR-143, miR-222, and miR-452 are useful as tumor stratification and noninvasive diagnostic biomarkers for bladder cancer. Am J Pathol 2012;180:1808-1815.

11 Mayer BJ, Hanafusa H: Mutagenic analysis of the v-crk oncogene: requirement for SH2 and SH3 domains and correlation between increased cellular phosphotyrosine and transformation. J Virol 1990;64:35813589.

12 Akagi T, Shishido T, Murata K, Hanafusa H: v-Crk activates the phosphoinositide 3-kinase/AKT pathway in transformation. Proc Natl Acad Sci U S A 2000;97:7290-7295.

-13 Linghu H, Tsuda M, Makino Y, Sakai M, Watanabe T, Ichihara S, Sawa H, Nagashima K, Mochizuki N, Tanaka S: Involvement of adaptor protein Crk in malignant feature of human ovarian cancer cell line MCAS. Oncogene 2006;25:3547-3556.

14 Matsumoto R, Tsuda M, Wang L, Maishi N, Abe T, Kimura T, Tanino M, Nishihara H, Hida K, Ohba Y, Shinohara N, Nonomura K, Tanaka S: Adaptor protein CRK induces epithelial-mesenchymal transition and 


\section{Cellular Physiology Cell Physiol Biochem 2018;45:366-377 \begin{tabular}{l|l|l} 
and Biochemistry $10.1159 / 000486908$ & $\begin{array}{l}\text { D 2 2018 The Author(s). Published by S. Karger AG, Basel } \\
\text { www.karger.com/cpb }\end{array}$ \\
\hline
\end{tabular}}

Li et al.: BDNF Val66Met Polymorphism is Associated with Bladder Cancer Risk

metastasis of bladder cancer cells through HGF/c-Met feedback loop. Cancer Sci 2015;106:709-717.

-15 Harrisberger F, Smieskova R, Schmidt A, Lenz C, Walter A, Wittfeld K, Grabe HJ, Lang UE, Fusar-Poli P, Borgwardt S: BDNF Val66Met polymorphism and hippocampal volume in neuropsychiatric disorders: A systematic review and meta-analysis. Neurosci Biobehav Rev 2015;55:107-118.

16 Lai PC, Chiu TH, Huang YT: Overexpression of BDNF and TrkB in human bladder cancer specimens. Oncol Rep 2010;24:1265-1270.

17 Hsu PK, Xu B, Mukai J, Karayiorgou M, Gogos JA: The BDNF Val66Met variant affects gene expression through miR-146b. Neurobiol Dis 2015;77:228-237.

18 Wu S, Ju GQ, Du T, Zhu YJ, Liu GH: Microvesicles derived from human umbilical cord Wharton's jelly mesenchymal stem cells attenuate bladder tumor cell growth in vitro and in vivo. PLoS One 2013;8:e61366.

19 Cocucci E, Racchetti G, Meldolesi J: Shedding microvesicles: artefacts no more. Trends Cell Biol 2009;19:4351.

20 Sidhu SS, Mengistab AT, Tauscher AN, LaVail J, Basbaum C: The microvesicle as a vehicle for EMMPRIN in tumor-stromal interactions. Oncogene 2004;23:956-963.

21 Dolo V, Ginestra A, Ghersi G, Nagase H, Vittorelli ML: Human breast carcinoma cells cultured in the presence of serum shed membrane vesicles rich in gelatinolytic activities. J Submicrosc Cytol Pathol 1994;26:173180.

-22 Wysoczynski M, Ratajczak MZ: Lung cancer secreted microvesicles: underappreciated modulators of microenvironment in expanding tumors. Int J Cancer 2009;125:1595-1603.

-23 Doeuvre L, Angles-Cano E: [Cell-derived microparticles unveil their fibrinolytic and proteolytic function]. Med Sci (Paris) 2009;25:37-44.

24 Dolo V, D’Ascenzo S, Violini S, Pompucci L, Festuccia C, Ginestra A, Vittorelli ML, Canevari S, Pavan A: Matrixdegrading proteinases are shed in membrane vesicles by ovarian cancer cells in vivo and in vitro. Clin Exp Metastasis 1999;17:131-140.

25 Calin GA, Croce CM: MicroRNA signatures in human cancers. Nat Rev Cancer 2006;6:857-866.

-26 Zhang B, Pan X, Cobb GP, Anderson TA: microRNAs as oncogenes and tumor suppressors. Dev Biol 2007;302:1-12.

27 Pignot G, Cizeron-Clairac G, Vacher S, Susini A, Tozlu S, Vieillefond A, Zerbib M, Lidereau R, Debre B, Amsellem-Ouazana D, Bieche I: microRNA expression profile in a large series of bladder tumors: identification of a 3-miRNA signature associated with aggressiveness of muscle-invasive bladder cancer. Int J Cancer 2013;132:2479-2491.

-28 Iorio MV, Ferracin M, Liu CG, Veronese A, Spizzo R, Sabbioni S, Magri E, Pedriali M, Fabbri M, Campiglio M, Menard S, Palazzo JP, Rosenberg A, Musiani P, Volinia S, Nenci I, Calin GA, Querzoli P, Negrini M, Croce CM: MicroRNA gene expression deregulation in human breast cancer. Cancer Res 2005;65:7065-7070.

29 Chen ZY, Patel PD, Sant G, Meng CX, Teng KK, Hempstead BL, Lee FS: Variant brain-derived neurotrophic factor (BDNF) (Met66) alters the intracellular trafficking and activity-dependent secretion of wild-type BDNF in neurosecretory cells and cortical neurons. J Neurosci 2004;24:4401-4411.

-30 Tettamanti G, Cattaneo AG, Gornati R, de Eguileor M, Bernardini G, Binelli G: Phylogenesis of brain-derived neurotrophic factor (BDNF) in vertebrates. Gene 2010;450:85-93.

-31 Wiener M, Lohoff FW, Coslett HB: Double dissociation of dopamine genes and timing in humans. J Cogn Neurosci 2011;23:2811-2821.

32 Fiore R, Khudayberdiev S, Christensen M, Siegel G, Flavell SW, Kim TK, Greenberg ME, Schratt G: Mef2mediated transcription of the miR379-410 cluster regulates activity-dependent dendritogenesis by finetuning Pumilio2 protein levels. EMBO J 2009;28:697-710.

-33 Huang YW, Ruiz CR, Eyler EC, Lin K, Meffert MK: Dual regulation of miRNA biogenesis generates target specificity in neurotrophin-induced protein synthesis. Cell 2012;148:933-946.

- 34 Mayer BJ, Hamaguchi M, Hanafusa H: A novel viral oncogene with structural similarity to phospholipase C. Nature 1988;332:272-275.

35 Lamorte L, Royal I, Naujokas M, Park M: Crk adapter proteins promote an epithelial-mesenchymal-like transition and are required for HGF-mediated cell spreading and breakdown of epithelial adherens junctions. Mol Biol Cell 2002;13:1449-1461.

-36 Watanabe T, Tsuda M, Makino Y, Ichihara S, Sawa H, Minami A, Mochizuki N, Nagashima K, Tanaka S: Adaptor molecule Crk is required for sustained phosphorylation of Grb2-associated binder 1 and hepatocyte growth factor-induced cell motility of human synovial sarcoma cell lines. Mol Cancer Res 2006;4:499-510.

37 Datta SR, Brunet A, Greenberg ME: Cellular survival: a play in three Akts. Genes Dev 1999;13:2905-2927. 